\title{
Safety and outcome using endoscopic dilation for benign esophageal stricture without fluoroscopy
}

\author{
E. R. Siddeshi, M. V. Krishna ${ }^{1}$, Deepak Jaiswal ${ }^{1}$, M. Murali Krishna ${ }^{1}$
}

Departments of Medical Gastroenterology, and ${ }^{1}$ General Medicine, Rajarajeswari Medical College and Hospital, Bengaluru, Karnataka, India

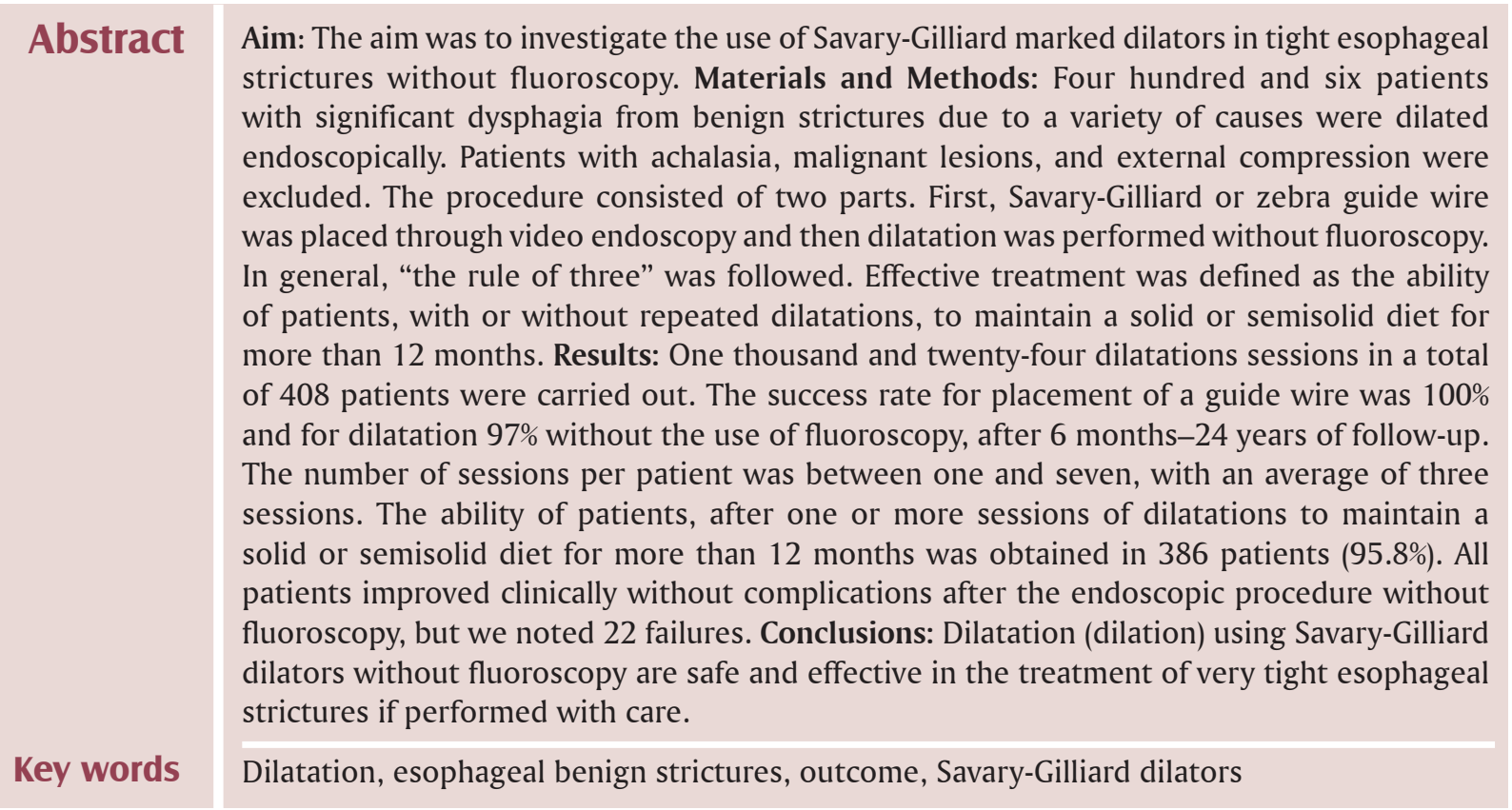

\section{Introduction}

Esophageal strictures are a problem frequently encountered by gastroenterologists and can be subdivided into malignant and of benign origin. Malignant esophageal strictures are mainly caused by primary esophageal cancer, but can also be caused by extra esophageal malignancies that compress the esophagus. ${ }^{[1]}$

\section{Address for correspondence:}

Dr. Deepak Jaiswal, Department of General Medicine, Rajarajeswari

Medical College and Hospital, Mysore Road, kumbipura, Bangalore 560074

India. E-mail: jaiswaldeepak2@gmail.com

\begin{tabular}{|l|c|}
\hline \multicolumn{2}{|c|}{ Access this article online } \\
\hline \multirow{2}{*}{$\begin{array}{l}\text { Website: } \\
\text { www.jdeonline.in }\end{array}$} & Quick Response Code \\
\hline DOI: & \\
10.4103/0976-5042.159236 & \\
\hline
\end{tabular}

The most common causes of benign esophageal strictures include peptic injury, Schatzki's ring, esophageal web, radiation injury, caustic injury, and anastomotic strictures.

Upper endoscopy is the diagnostic procedure of choice for the detection of an esophageal stricture and its underlying cause. Nevertheless, it is mandatory that biopsy samples are taken to confirm whether the stricture is benign or malignant in nature. ${ }^{[1]}$

Dilatation of esophageal strictures is a commonly performed procedure used, to relieve dysphagia. In clinical practice, fluoroscopy is recommended for monitoring the position of

This is an open access article distributed under the terms of the Creative Commons Attribution-NonCommercial-ShareAlike 3.0 License, which allows others to remix, tweak, and build upon the work non-commercially, as long as the author is credited and the new creations are licensed under the identical terms.

For reprints contact: reprints@medknow.com

How to cite this article: Siddeshi ER, Krishna MV, Jaiswal D, Krishna MM. Safety and outcome using endoscopic dilation for benign esophageal stricture without fluoroscopy. J Dig Endosc 2015;6:55-8. 
a guide wire and dilator. ${ }^{[2-5]}$ Some authors, however, believe that fluoroscopy is not necessary for dilatation. The aim of this study was to describe our experience using a guide wire and marked Savary-Gilliard like dilators (indigenous) without the use of fluoroscopy.

\section{Materials and Methods}

\section{Patients}

Between July 1989 and December 2014, 408 consecutive patients (226 males, 182 females, aged between 18 and 75 years old, mean age 42 years) with benign esophageal strictures were referred to our department for dilatation because of persistent or recurrent dysphagia. Benign stricture was ascertained using endoscopy and biopsy. There were 408 benign stricture patients. The diagnosis is summarized in Table 1. Patients with achalasia, malignant lesions, and external compression were excluded with relevant investigations. All our patients had various degrees of dysphagia. A total of 1224 dilations were performed for 408 patients who had various degrees of dysphagia prior to each session. X-ray studies of the geography of the strictures were performed for cases before treatment where the lumen beyond the stricture is not accessible.

\section{Instruments}

Examinations were performed with EPK 3300, 3500/2931 pentax scopes. Dilatation was performed with marked Savary-Gilliard (indeginous) like dilators using Savary-Gilliard or zebra guide wire.

\begin{tabular}{lc}
\hline \multicolumn{2}{l}{ Table 1: Etiologies of esophageal benign strictures } \\
\hline Benign strictures & $\boldsymbol{n}(\%)$ \\
\hline Peptic injury & $208(50.98)$ \\
Plummer-Vinson web (postcricoid web) & $34(8.33)$ \\
Radic stricture & $96(23.52)$ \\
Caustic stricture (corrosive) & $28(6.86)$ \\
Anastomotic stricture & $32(7.84)$ \\
(Schatzki ring) (GERD) & $10(2.45)$ \\
\hline
\end{tabular}

GERD: Gastro-oesophageal reflux disease

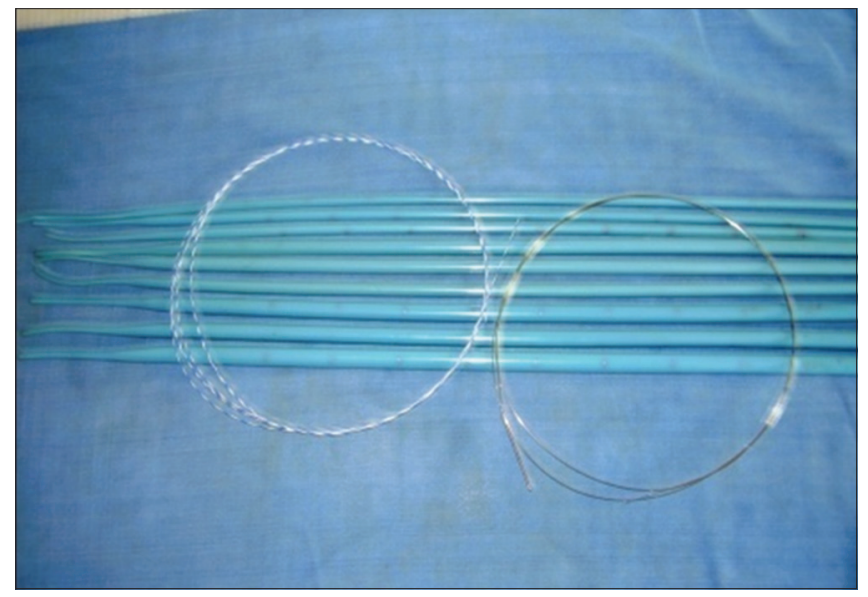

Figure 1: Savary-Gilliard dilator with guided wire

\section{Technique}

With $10 \%$ xylocaine spray to the throat, the guide wire was placed through the stricture under endoscopic guidance. Thereafter, dilatation was performed without fluoroscopy. Five millimeter (thin) dilator was used over the guide wire to reassess the position of guide wire. In general, "the rule of three-dilators size increased step by step" was carried out. If dysphagia and esophageal strictures recurred during the clinical follow-up after completion of a series of dilatations, additional dilatation was carried out until symptomatic relief was achieved. All procedures were performed without any sedation (throat $10 \%$ xylocaine spray only).

\section{Results}

Peptic injury was the most frequent cause of esophageal benign stricture in our series in $41.6 \%$ of patients, followed by radic stricture in $27.7 \%$ of cases [Table 1].

A total of 1224 dilatations in 408 patients were performed. The success rate for the placement of a guide wire was $100 \%$ and for dilatation was $97 \%$, without the use of fluoroscopy, after 2 months-24 years of follow-up. We performed an endoscopy immediately, post-procedure to look for any bleeding or mucosal tearing. After dilatation, our patients are observed for $6 \mathrm{~h}$. They are clinically examined and in case of persisting pain, chest X-ray was carried out to check for any perforation. Twenty-four hours after dilatation, we asked our patients to phone if there is any fever or pain. In our series, there were no adverse events or complications and patients followed up monthly to once in 3 months. Thereafter once in 6 months.

The number of sessions per patient was between one and seven, with an average of three sessions.

The ability of patients after one or more sessions of dilatations to maintain a solid or semisolid diet for more than 12 months was obtained in 386 patients $(95.8 \%)$.

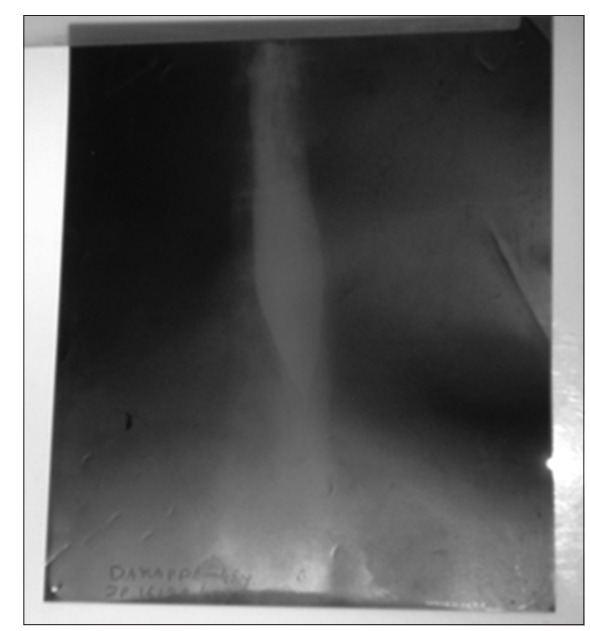

Figure 2: X-ray showing stricture on barium swallow 


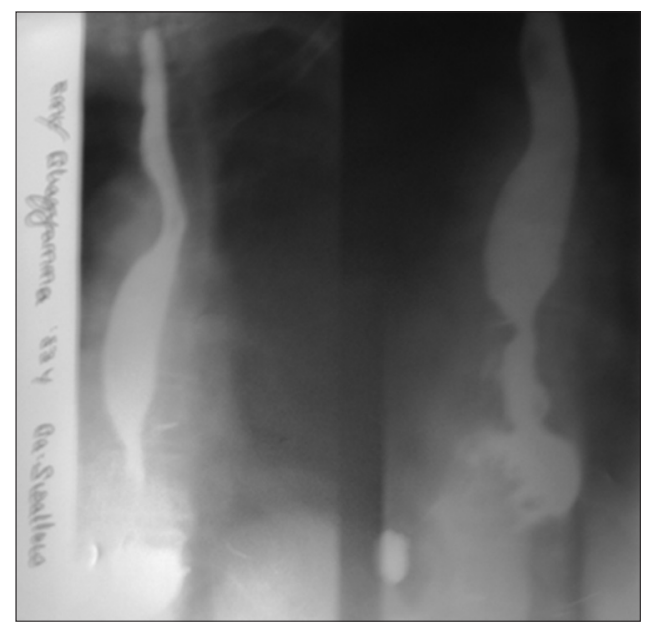

Figure 3: X-ray showing stricture on barium swallow

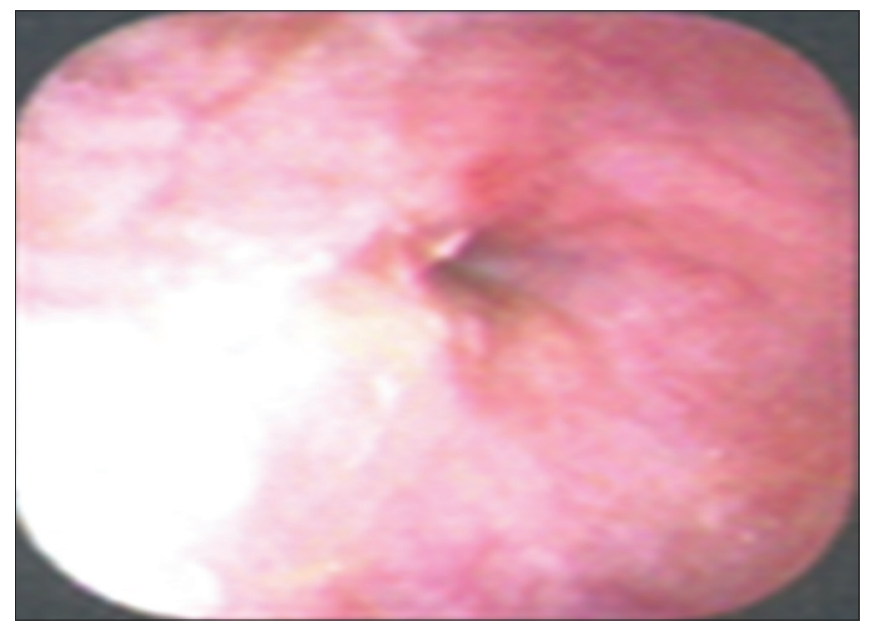

Figure 4: Endoscopy showing peptic stricture

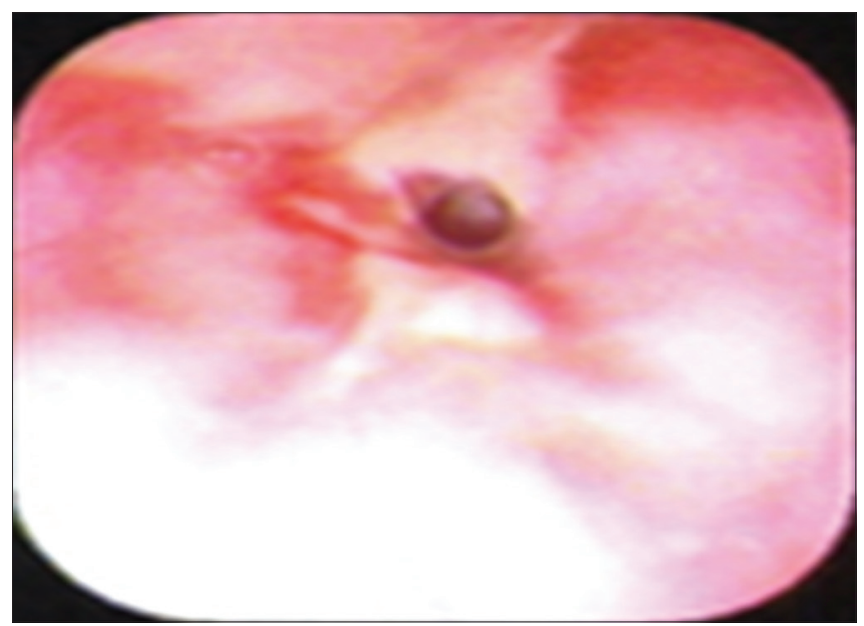

Figure 5: Endoscopy showing radiation stricture

For very tight esophageal strictures, we placed the guide wire through the tight stricture into the lumen, initially dilated without complications. All patients with very tight strictures had clinical improvement, but we noted 22 endoscopic dilatation failures; eight patients with anastomotic strictures because of tumoral recurrence and nine patients with radic stenosis, five with corrosive strictures. Ninety-six patients who had dilation for 1-year, 76 patients showed recurrence of tumor after 1-5 years of follow-up [Figures 1-5].

\section{Discussion}

Benign esophageal strictures are secondary to different causes. In our series, peptic injury was the most frequent lesion, as found in the literature.

The mainstay of treatment for benign esophageal strictures is dilatation. Although dilatation usually results in symptomatic relief, recurrent strictures do occur. In order to predict which types of strictures are most likely to recur, it is important to differentiate between esophageal strictures that are simple and those that are more complex. ${ }^{[1,6]}$ Simple esophageal strictures are defined as focal and straight. ${ }^{[1,6]}$ Common etiologies include peptic injury (60-70\% of cases) and a radic injury. ${ }^{[6,7]}$ In most patients with simple esophageal strictures, one to three dilatations are required to relieve symptoms, with an additional $25-35 \%$ of patients requiring repeat dilatations. In our series, $76 \%$ of patients had simple esophageal strictures and needed from one to three sessions of dilations.

Strictures that are long $(>2 \mathrm{~cm})$ and tortuous are defined as complex esophageal strictures. ${ }^{[6]}$ The most common causes include caustic ingestion, ${ }^{[8]}$ radiation injury, anastomotic stricture, ${ }^{[9]}$ and severe peptic injury. Complex esophageal strictures are most difficult to treat than simple esophageal strictures, require at least three dilatation sessions to relieve symptoms, and are associated with high recurrence rates. If complex strictures cannot be dilated to an adequate diameter that allows passage of solid food, recur within a time interval of 2-4 weeks or require ongoing (more than seven to ten sessions) dilatations, they are considered to be refractory. ${ }^{[6]}$ Novel treatment modalities for refractory stricture include temporary stent placement and incision therapy. ${ }^{[1]}$ In our series, $24 \%$ were complex esophageal strictures, caused by radiation injury, caustic ingestion, and anastomotic stricture.

Successful esophageal dilatation involves both successful placement of the guide wire and dilation. This study demonstrates that Savary-Gilliard dilation can be successful without fluoroscopic control. There were, no procedure induced complications. All 408 unselected consecutive patients had significant dysphagia due to different types of esophageal benign pathology. Symptom relief was achieved in 386 patients. The results are similar to that reported by four authors. ${ }^{[5,10,11]}$ However, in two studies, the endoscope was impassable in $5 \%$ and $29.4 \%$. For these cases, fluoroscopy was required. During the insertion of the wire, if there is resistance or if the patient starts coughing (which indicates that the wire is inserted into the trachea through the fistula), the wire should be withdrawn and reinserted. In order to prevent complications, 
the "rule of three" was popularized by Boyce. ${ }^{[12]}$ Dilatation should be terminated when resistance is encountered during these consecutive dilations.

The main complications associated with esophageal dilatation include perforation (can occur in $0.5-1.2 \%$ ), ${ }^{[13,14]}$ hemorrhage and bacteremia. The reported rate of perforation and massive bleeding is $0.3 \%$; this risk is higher with complex strictures ${ }^{[15]}$ and caustic strictures. ${ }^{[8]}$ It is generally believed that the risk of perforation is minimal if the "rule of three" is applied, meaning that dilation diameters should not increase by more than $3 \mathrm{~mm}$ per session. ${ }^{[6]}$ Predilation diameter and stricture length are established factors that influence the number of dilations required for symptom relief and the need for additional dilations. ${ }^{[16]}$

In conclusion, careful placement of a guide wire prior to dilation is crucial to achieve successful dilation. With the technique of through the scope guide wire insertion, endoscopic dilatation without fluoroscopy is a safe and efficacious way to relieve dysphagia, especially in benign simple strictures. Repeated sessions are necessary to avoid recurrence.

\section{Financial support and sponsorship Nil.}

\section{Conflict of interest}

There are no conflict of interest.

\section{References}

1. Siersema PD. Treatment options for esophageal strictures. Nat Clin Pract Gastroenterol Hepatol 2008;5:142-52.
2. Bennett JR, Hunt RH. Therapeutic Endoscopy and Radiology of the Gut. $2^{\text {nd }}$ ed. New York: Chapman and Hall Med; 1990. p. 19-20.

3. Cotton PB, Williams CP. Practical Gastrointestinal Endoscopy. $3^{\text {nd }}$ ed. Oxford: Blackwell Science Publishers; 1990. p. 59-61.

4. Geenen JE, Fleischer DE, Waye JD. Techniques in Therapeutic Endoscopy. $2^{\text {nd }}$ ed., Vol. 2. New York: Gower Medical Publishing; 1992. p. 9-11.

5. Wang YG, Tio TL, Soehendra N. Endoscopic dilation of esophageal stricture without fluoroscopy is safe and effective. World J Gastroenterol 2002;8:766-8.

6. Lew RJ, Kochman ML. A review of endoscopic methods of esophageal dilation. J Clin Gastroenterol 2002;35:117-26.

7. Pereira-Lima JC, Ramires RP, Zamin I Jr, Cassal AP, Marroni CA, Mattos AA. Endoscopic dilation of benign esophageal strictures: Report on 1043 procedures. Am J Gastroenterol 1999;94:1497-501.

8. Poley JW, Steyerberg EW, Kuipers EJ, Dees J, Hartmans R, Tilanus HW, et al. Ingestion of acid and alkaline agents: Outcome and prognostic value of early upper endoscopy. Gastrointest Endosc 2004;60:372-7.

9. Honkoop P, Siersema PD, Tilanus HW, Stassen LP, Hop WC, van Blankenstein M. Benign anastomotic strictures after transhiatal esophagectomy and cervical esophagogastrostomy: Risk factors and management. J Thorac Cardiovasc Surg 1996;111:1141-6.

10. Fleischer DE, Benjamin SB, Cattau EL Jr, Collen MJ, Lewis JH, Jaffee MH, et al. A marked guide wire facilitates esophageal dilatation. Am J Gastroenterol 1989;84:359-61.

11. Kadakia SC, Cohan CF, Starnes EC. Esophageal dilation with polyvinyl bougies using a guidewire with markings without the aid of fluoroscopy. Gastrointest Endosc 1991;37:183-7.

12. Boyce HW. Esophageal dilation. Gastroenterol Endosc News 1986:1-3.

13. Andreollo NA, Lopes LR, Inogutti R, Brandalise NA, Leonardi LS. Conservative treatment of benign esophageal strictures using dilation. Analysis of 500 cases. Rev Assoc Med Bras 2001;47:236-43.

14. Saeed ZA, Winchester CB, Ferro PS, Michaletz PA, Schwartz JT, Graham DY. Prospective randomized comparison of polyvinyl bougies and through-the-scope balloons for dilation of peptic strictures of the esophagus. Gastrointest Endosc 1995;41:189-95.

15. Hernandez LV, Jacobson JW, Harris MS. Comparison among the perforation rates of Maloney, balloon, and savary dilation of esophageal strictures. Gastrointest Endosc 2000;51:460-2.

16. Chiu YC, Hsu CC, Chiu KW, Chuah SK, Changchien CS, Wu KL, et al. Factors influencing clinical applications of endoscopic balloon dilation for benign esophageal strictures. Endoscopy 2004;36:595-600. 